\title{
THE CHARACTERISATION AND PREDICTION OF LCF BEHAVIOUR IN NICKEL SINGLE CRYSTAL BLADE ALLOYS
}

\author{
W.J. Evans ${ }^{1}$, R. Lancaster ${ }^{1}$, A. Steele ${ }^{1}$ and N. Jones ${ }^{2}$ \\ ${ }^{1}$ Materials Research Centre, School of Engineering, Swansea University, Singleton Park, Swansea SA2 8PP \\ ${ }^{2}$ Rolls-Royce plc, P O Box 31, Elton Road, Derby, DE24 8BJ
}

Keywords: CMSX4, Alloy variants, strain control fatigue, notch fatigue, casting pores, life prediction

\begin{abstract}
The paper focuses on CMSX4 and two experimental alloys, LDSX5 and LDSX6, developed to provide alternative performance attributes. The specific objective in this work was an exploration of the Low Cycle Fatigue (LCF) characteristics of these three alloy variants and the assessment of methods for predicting the observed lives. A comparison of the alloys is presented in relation to their strain control fatigue response and notch fatigue behaviour. Predictions of notch lives are made from the plain specimen data but found to be extremely pessimistic at the lower temperature studied, $650^{\circ} \mathrm{C}$. The inaccuracies are attributed to the presence of casting pores. Using measured crack growth data and pore sizes, it is shown that fracture mechanics calculations of residual lives are more appropriate. At $800^{\circ} \mathrm{C}$, the higher temperature studied, Walker strain predictions of notch lives are more meaningful. This is explained in terms of the relaxation of stresses at the defects.
\end{abstract}

\section{Introduction}

The research programme set out to explore the LCF behaviour of experimental single crystal nickel alloys. The alloys specifically focused on alternative compositions to CMSX4 that offer various performance attributes. The two alloys highlighted in the present paper were chosen because of lower densities, improved stability (LDSX5) and enhanced creep strength (LDSX6). Data generated on CMSX4 were used for comparison. All alloys were produced with a [100] orientation using conventional single crystal casting technology. The experiments involved plain and notched testpieces with $\mathrm{K}_{\mathrm{t}}$ values of 2.38 for a centre hole plus 2.3 and 3.6 for double edge notch geometries. Plain specimens were subjected to $15 \mathrm{cpm}$ strain control fatigue with $\mathrm{R}$ values of 0 and -1 . From these tests, hysteresis loops were recorded and cyclic stress-strain curves constructed. The notch specimens were tested with the same waveform at $\mathrm{R}=0$. Plain and notched specimens were tested at $650^{\circ} \mathrm{C}$ and $800^{\circ} \mathrm{C}$. The orientations of test-pieces and notches were confirmed to be consistent by means of Electron BackScatter Diffraction (EBSD) measurements.

A prime objective of the work was the assessment of methods for predicting fatigue performance. In particular, the Walker strain relationship has previously been shown to provide an effective means of predicting notch behaviour $[1,2]$. In the present situation, however, inconsistencies were identified which were attributed to the presence of casting pores. These defects introduced the need to consider an alternative damage tolerance approach based on fracture mechanics and the application of crack growth rate data. Both life prediction methods are highlighted and discussed.

\section{Experimental Procedures}

\section{The Alloys}

The compositions of the LDSX5 and LDSX6 alloys are summarised in Table I in relation to CMSX4.

Table I. Alloy Compositions (wt\%)

\begin{tabular}{|l|c|c|c|c|c|c|c|c|c|c|}
\hline & Co & $\mathrm{Cr}$ & $\mathrm{Mo}$ & $\mathrm{W}$ & $\mathrm{Re}$ & $\mathrm{Ru}$ & $\mathrm{Al}$ & $\mathrm{Ti}$ & $\mathrm{Ta}$ & $\mathrm{Hf}$ \\
\hline LDSX5 & 8.4 & 3.1 & 2.7 & 2.9 & 6.4 & 4.6 & 5.6 & 0.3 & 6.5 & 0.1 \\
\hline LDSX6 & 3.1 & 3.3 & 2.7 & 4.8 & 6.4 & 4.7 & 5.6 & 0.3 & 6.5 & 0.1 \\
\hline CMSX4 & 9 & 6.4 & 0.6 & 6.4 & 3 & 0 & 5.6 & 1 & 6.5 & 0.1 \\
\hline
\end{tabular}

The principal differences from CMSX4 are a higher rhenium content, the addition of ruthenium, greater amount of molybdenum and reduced tungsten particularly for LDSX5. This is illustrated in figure 1. These changes influenced density, stability, creep strength and castability. The relative benefits are highlighted in Table II.

Table II. Relative attributes of the alloys

\begin{tabular}{l|lllll} 
Stability & LDSX5 & LDSX6 & $>$ & CMSX4 \\
Creep strength & CMSX4 $>$ LDSX6 & $>$ LDSX5 \\
Castability & CMSX4 & $>$ LDSX5 & $>$ & LDSX6
\end{tabular}

Following casting the alloys were solution treated at $1340^{\circ} \mathrm{C}$, gasfan quenched, primary aged at $1150^{\circ} \mathrm{C}$, quenched and finally aged at $870^{\circ} \mathrm{C}$. Microstructures were defined by etching in $10 \mathrm{ml} \mathrm{HNO}_{3}$, $50 \mathrm{ml} \mathrm{HCl}, 2.5 \mathrm{~g} \mathrm{Cucl}_{2}$ and $40 \mathrm{ml} \mathrm{H}_{2} 0$. Scanning Electron Microscopy (SEM) comparisons of LDSX5 and LDSX6 at the same magnification are reproduced in figures 2 and 3.

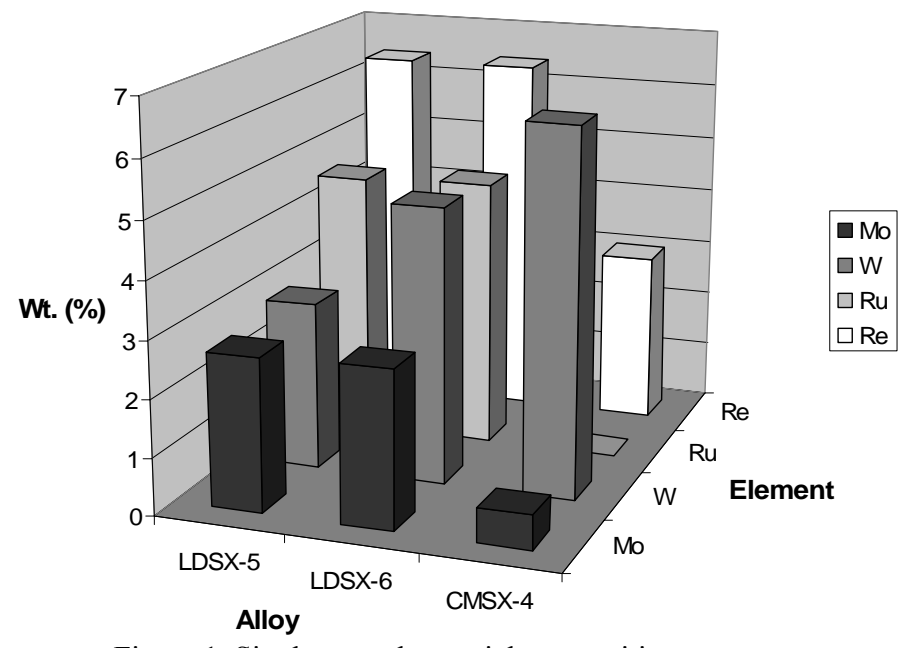

Figure 1. Single crystal material compositions 


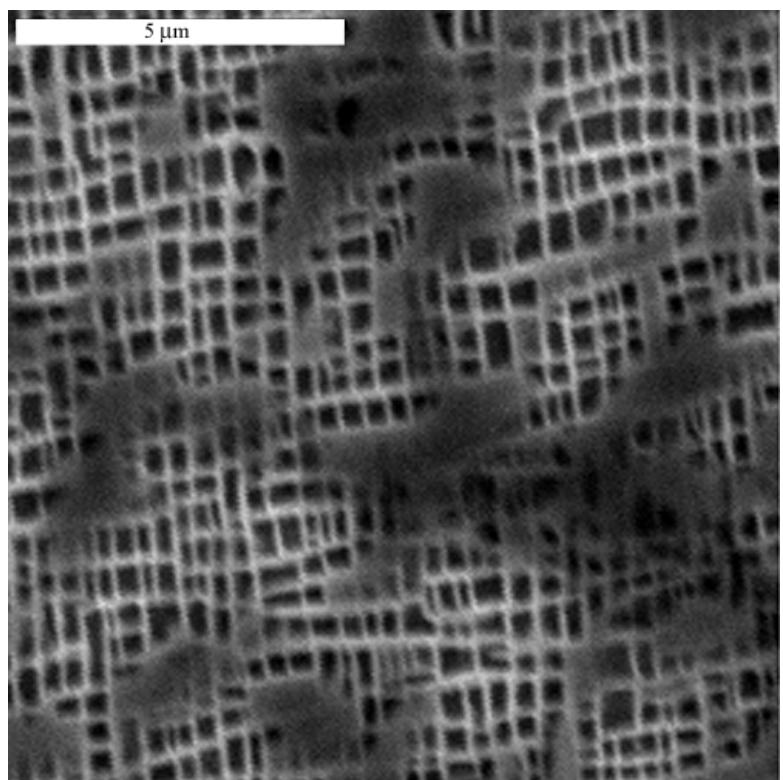

Figure 2. Microstructure of LDSX5

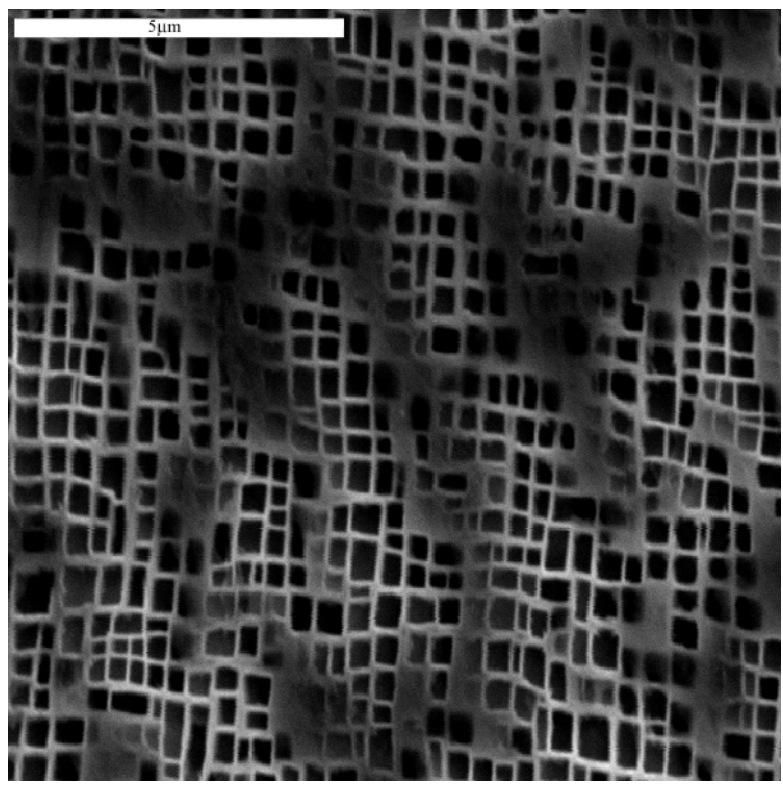

Figure 3. Microstructure of LDSX6

The average measured widths of the $\gamma^{\prime}$ precipitates and $\gamma$ channels are recorded in Table III.

Table III. Microstructural measurements

\begin{tabular}{|c|c|c|}
\hline Alloy & $\begin{array}{c}\text { Average width of } \\
\gamma^{\prime},(\mu \mathrm{m})\end{array}$ & $\begin{array}{c}\text { Average width of } \gamma \\
\text { channels }(\mu \mathrm{m})\end{array}$ \\
\hline LDSX5 & 0.36 & 0.136 \\
\hline LDSX6 & 0.41 & 0.136 \\
\hline CMSX4 & 0.45 & 0.15 \\
\hline
\end{tabular}

All the alloys contained casting pores. Typical examples are illustrated in figure 4 . These pores played an important role in the observed fatigue behaviour. They will be considered in more detail during the discussion.

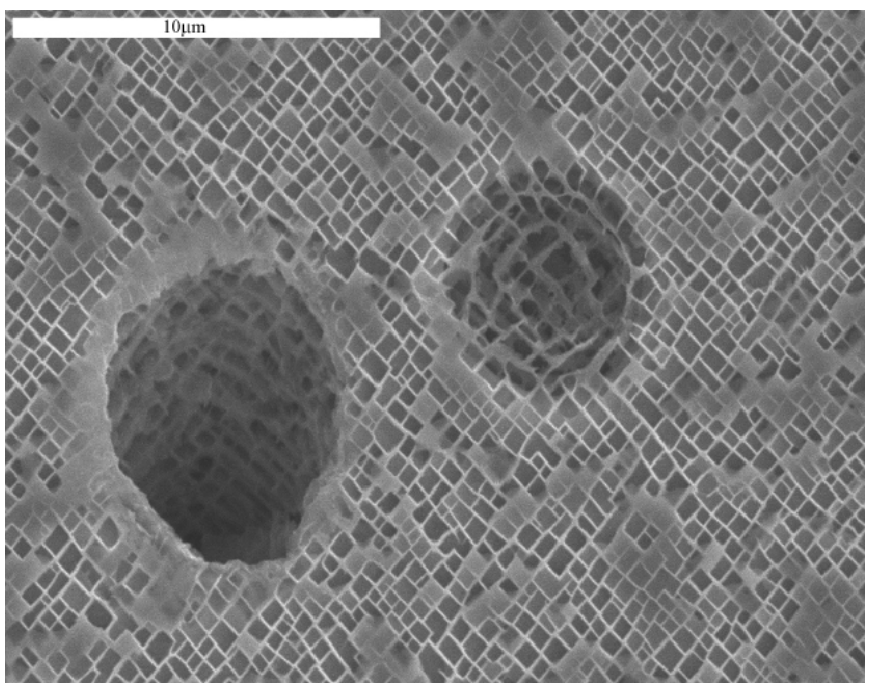

Figure 4. Typical pores in CMSX4

Fatigue Procedures

The core fatigue tests were carried out under strain control on a plain cylindrical specimen with a gauge length of $15 \mathrm{~mm}$ and a nominal $5 \mathrm{~mm}$ diameter. Two sets of the notched specimens had a DEN (Double Edge Notch) configuration with $\mathrm{K}_{\mathrm{t}}$ values of 2.3 and 3.6. The third set had a 'flat plate' geometry with a $\mathrm{K}_{t}$ value of 2.38. The three notch specimens are shown in figure 5 .
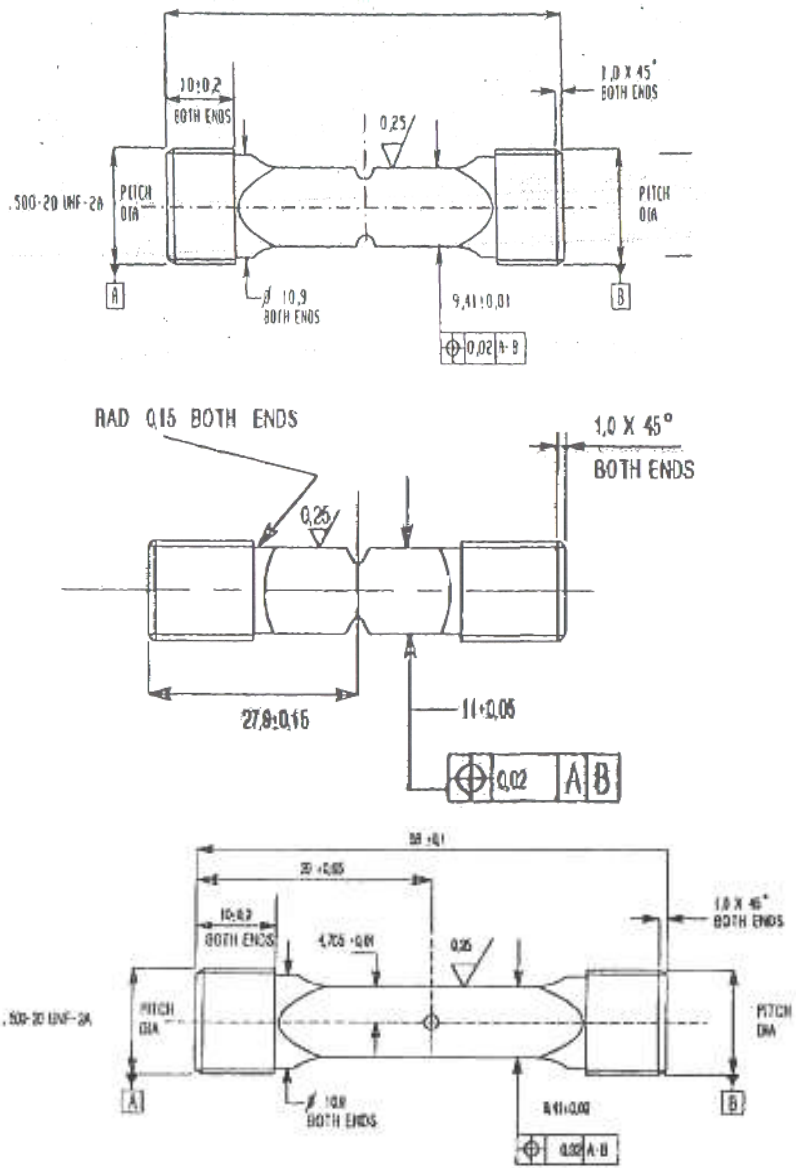

Figure 5. Form and dimensions of the three notch specimens 
Additional crack propagation measurements were made on a corner crack specimen with a $7 \times 7 \mathrm{~mm}$ cross section and a $0.35 \mathrm{~mm}$ deep slit machined into one corner. The cast bars from which all specimens were machined were aligned so that their primary axis (specimen longitudinal direction) was $<20^{\circ}$ from [001] direction. An EBSD analysis confirmed that in practice, misalignment amounted to only a few degrees. The analysis also demonstrated that the alignment of notches in the DEN specimens was consistent throughout the whole batch of specimens.

The low cycle fatigue tests complied with the British Standards BS3518: part 1: 1993 for load controlled notch testing and BS7270:1990 for the strain control testing of plain specimens. For all tests a 1-1-1-1 trapezoidal waveform at a frequency of $0.25 \mathrm{~Hz}$ was applied. The load control tests were carried out at $\mathrm{R}=0$ but the strain control measurements involved both $\mathrm{R}=0$ and 1. The experiments encompassed temperatures of $650^{\circ} \mathrm{C}$ and $800^{\circ} \mathrm{C}$ although the majority of the work involved the former. The temperatures were achieved by means of a conventional air furnace with two type $\mathrm{K}$ or $\mathrm{N}$ thermocouples attached close to the centre of the specimen gauge length. A uniform temperature distribution to within $\pm 1^{\circ} \mathrm{C}$ was maintained for the duration of the tests. For the strain control experiments, the extensometer, with an extension range of $0.25 \mathrm{~mm}$ and a position range or gauge length of $10 \mathrm{~mm}$, was recalibrated before each test and prior to heating.

The crack propagation tests involved $\mathrm{R}=-1,0$ and 0.5 load ratios and the standard 1-1-1-1 trapezoidal waveform. Crack growth was monitored by a direct current potential difference method in which the constant current was pulsed to minimise heating effects. On conversion of the voltage changes to increases in crack length with cycles, the rate of crack growth $(\mathrm{da} / \mathrm{dN})$ was determined by means of a three point secant approach.

All fractured specimens were examined in the SEM to define crack path features including casting pores and their depth below the specimen surface. EBSD was also used to confirm the orientation of all test pieces in relation to notches and crack growth directions.

\section{Experimental Results}

\section{$\underline{\text { Cyclic Stress-Strain Curves }}$}

The strain control measurements allowed key material property characteristics to be defined. The important parameters involved monotonic and cyclic yield strengths, ultimate strengths and amount of stress relaxation associated with each temperature. Cyclic stress-strain curves derived from the measured hysteresis loops are illustrated for CMSX4 and the two alloy variants at $650^{\circ} \mathrm{C}$ in figure 6. A similar graph for CMSX4 at $650^{\circ} \mathrm{C}$ and $800^{\circ} \mathrm{C}$ is shown in figure 7 .

Several important deductions can be made from figures 6 and 7:

- The monotonic stress-strain curves for CMSX4 at $650^{\circ} \mathrm{C}$ and $800^{\circ} \mathrm{C}$ almost superimpose although there is a slight reduction in modulus with temperature.
- The monotonic strengths of LDSX5 and 6 are lower than CMSX4 but alloy 6 has a higher rate of strain hardening.

- The CMSX-4 does not cyclically soften at $650^{\circ} \mathrm{C}$ and in fact tends to cyclically harden.

- In contract the $\mathrm{CMSX}-4$ at $800^{\circ} \mathrm{C}$ displays significant cyclic softening

- Both LDSX 5 and 6 at $650^{\circ} \mathrm{C}$ do not cyclically soften.

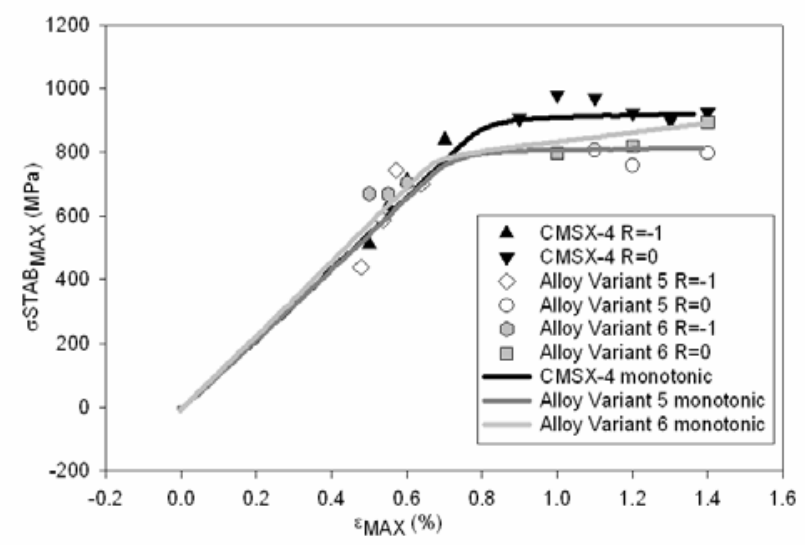

Figure 6. Monotonic and cyclic stress-strain response of CMSX4, LDSX 5 and LDSX6 at $650^{\circ} \mathrm{C}$

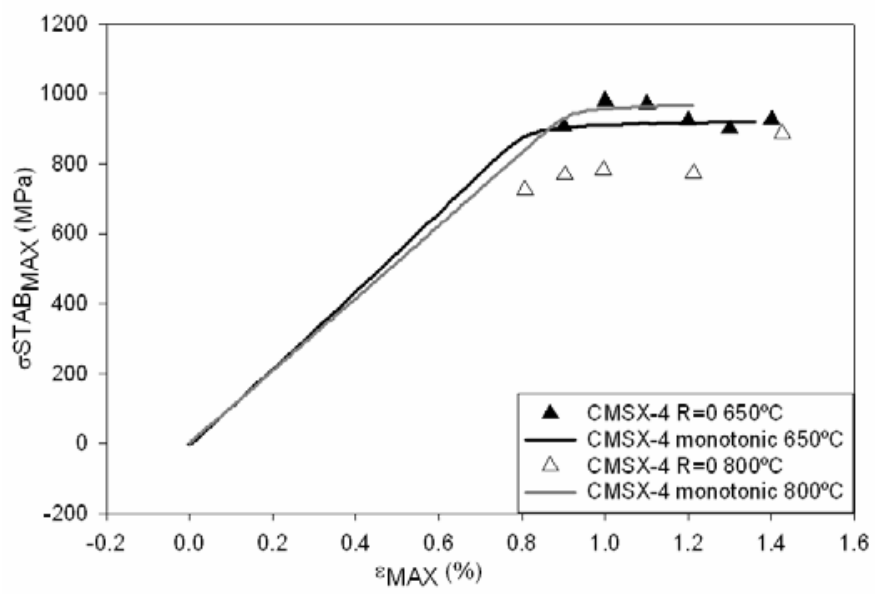

Figure 7. Monotonic and cyclic stress-strain response of CMSX4 at $650^{\circ} \mathrm{C}$ and $800^{\circ} \mathrm{C}$

Figure 8 illustrates the strain range-life response of CMSX4 at $650^{\circ} \mathrm{C}$ and $800^{\circ} \mathrm{C}$ and the two other variants at $650^{\circ} \mathrm{C}$. Upper and lower bound curves have been super-imposed on the graph. The CMSX4 sits largely in the upper band although there are exceptions. The $\mathrm{R}=0$ data for $\mathrm{CMSX} 4$ at 650 and $800^{\circ} \mathrm{C}$ generally lie on the dashed line that merges with the upper band. The apparent difference for this alloy between $\mathrm{R}=-1$ and $\mathrm{R}=0$ is not unusual and has been recorded for other systems. LDSX5 and 6 are generally consistent with the lower band but once again there are exceptions. It is believed that the variability is associated with crack initiation at pre-existing pores. 


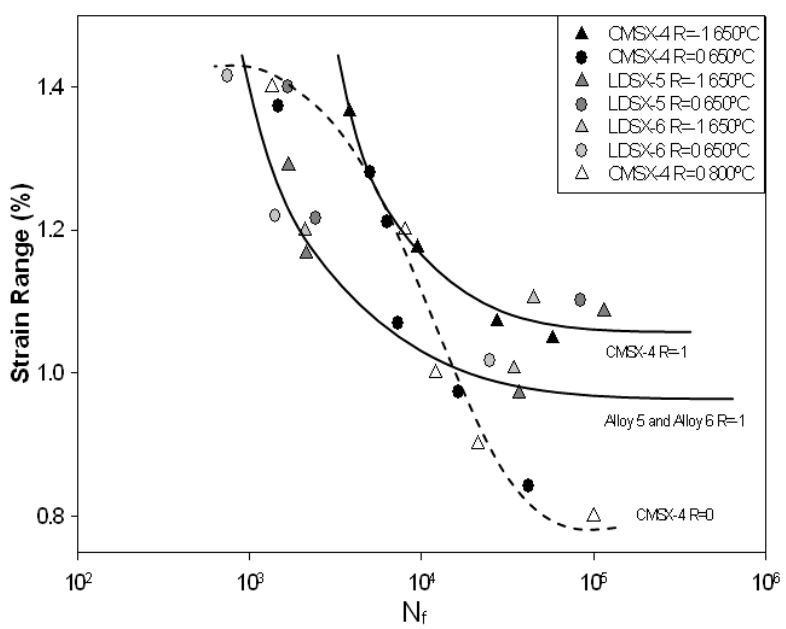

Figure 8. LCF Strain Range response of CMSX4, LDSX5 and LDSX6

\section{Notch Fatigue}

Notch behaviour at $650^{\circ} \mathrm{C}$ and $800^{\circ} \mathrm{C}$ is recorded in figure 9 . The fatigue data are plotted in terms of peak elastic stress $\left(\mathrm{K}_{\mathrm{t}} \sigma_{\mathrm{nom}}\right)$. There is significant scatter particularly at $650^{\circ} \mathrm{C}$. This is attributed to the role of casting pores in crack initiation. Even so there are trends. Thus LDSX6 displays a longer life for the $\mathrm{K}_{\mathrm{t}}=3.6$ notches. This may be associated with the higher, monotonic strain hardening characteristic of this alloy. The $\mathrm{K}_{\mathrm{t}}=3.6$ data for LDSX5 and CMSX4 effectively superimpose within the observed scatter even though the alloy variant is weaker monotonically and in the strain control experiments. The only common feature of the two alloys is the rate of strain hardening both monotonically and cyclically which would influence the extent of plasticity at the notch root.

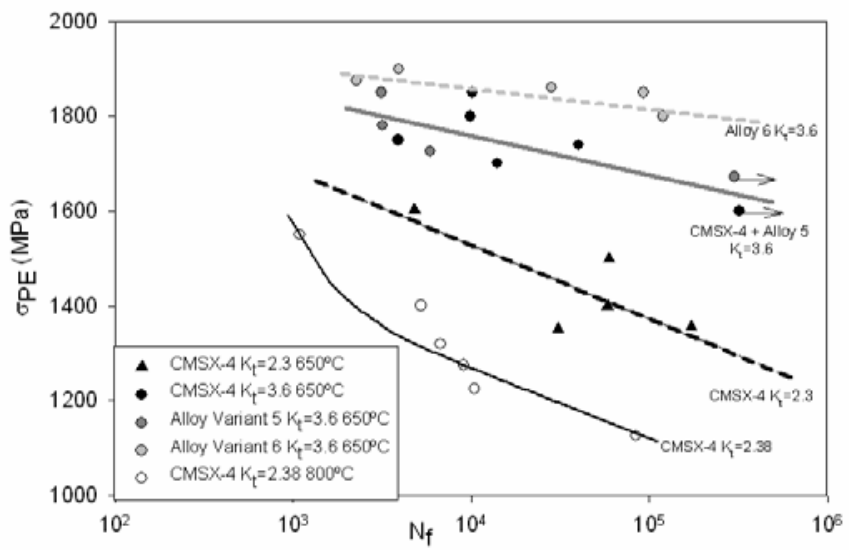

Figure 9. Notch behaviour at $650^{\circ} \mathrm{C}$ and $800^{\circ} \mathrm{C}$ for different $\mathrm{K}_{\mathrm{t}}$ values

\section{Casting Pores and Variability}

The test results highlight the role of casting pores in the fatigue performance of both plain and notched specimens. Virtually all fracture surfaces displayed evidence of porosity. However, it was not always evident that a pore was responsible for crack initiation.
Some examples of pores and fracture surfaces from strain control specimens are illustrated in figures 10 and 11.

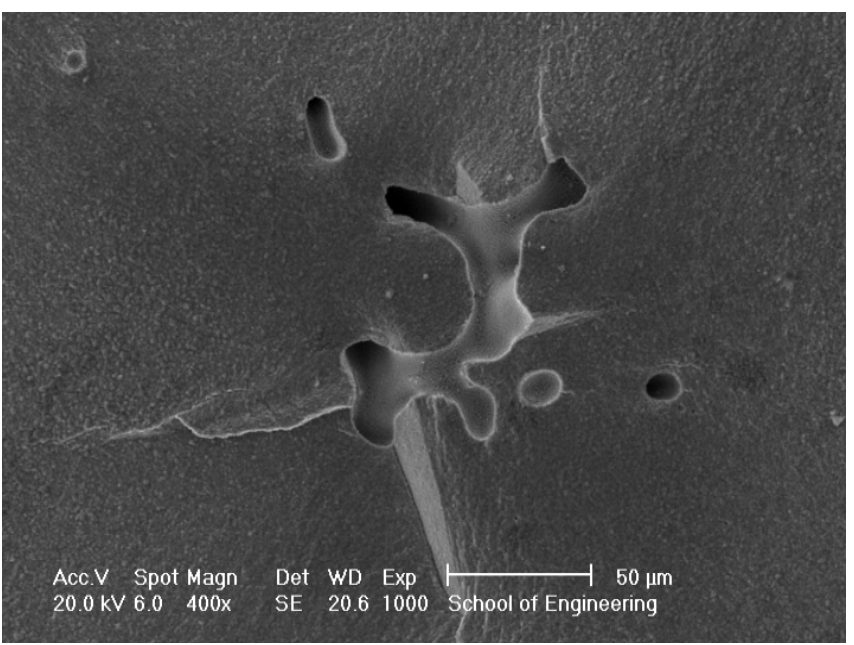

Figure 10. Casting pore in plain CMSX4 specimen at $650^{\circ} \mathrm{C}$

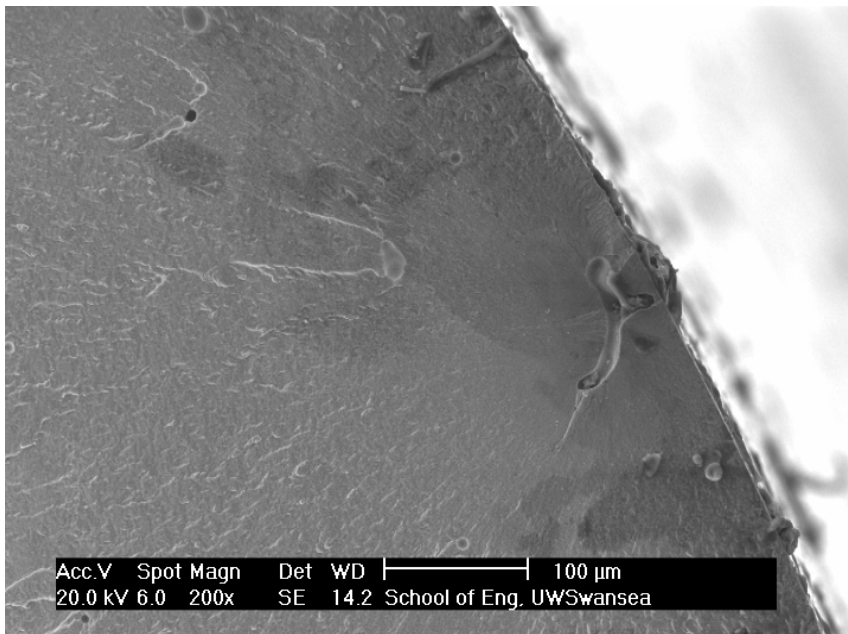

Figure 11. Casting pore in plain LDSX6 specimen at $650^{\circ} \mathrm{C}$

Table IV. Repeat strain control tests at $\Delta \varepsilon=1 \%$

\begin{tabular}{|c|c|c|c|c|}
\hline Nf & $\begin{array}{c}\text { Peak } \\
\text { Stress } \\
(\mathrm{MPa})\end{array}$ & $\begin{array}{c}\text { Stress } \\
\text { Range } \\
(\mathrm{MPa})\end{array}$ & $\begin{array}{c}\text { Pore Size } \\
\left(\mu \mathrm{m}^{2}\right)\end{array}$ & $\begin{array}{c}\text { Pore } \\
\text { Distance } \\
(\mu \mathrm{m})\end{array}$ \\
\hline 12311 & 903.9 & 1188.8 & 19905 & 1750 \\
\hline 9983 & 891 & 1172.3 & 7057 & 100 \\
\hline 10997 & 892.8 & 1216.6 & 24328 & 50 \\
\hline 11465 & 1009.1 & 1135 & 5341 & 250 \\
\hline 15894 & 972.4 & 1145.1 & 6231 & 980 \\
\hline
\end{tabular}

It is believed that the observed variability in fatigue performance is a direct consequence of the pores and their position on the fracture surface. To explore this belief a series of repeat strain control and notch tests were carried at a strain range of $1 \%$ and peak elastic stress of $1750 \mathrm{MPa}$ respectively. The measured lives together with other supporting information are recorded in Table IV and $\mathrm{V}$. 
Table V. Repeat $\mathrm{K}_{\mathrm{t}}=3.6$ notch tests at $\mathrm{K}_{\mathrm{t}} \sigma_{\max }=1750 \mathrm{MPa}$

\begin{tabular}{|c|c|c|c|}
\hline Nf & Ratio & $\begin{array}{c}\text { Pore Size } \\
\left(\mu \mathrm{m}^{2}\right)\end{array}$ & $\begin{array}{c}\text { Pore distance } \\
(\mu \mathrm{m})\end{array}$ \\
\hline 4993 & 0.75 & 52 & 39 \\
\hline 50113 & 5.55 & 20 & 111 \\
\hline 8361 & 0.013 & 1227 & 17 \\
\hline 17682 & 0.759 & 362 & 275 \\
\hline 29563 & 0.03 & 1100 & 33 \\
\hline 3899 & 0.0488 & 655 & 32 \\
\hline
\end{tabular}

The scatter in lives observed is consistent with the original data in figures 8 and 9. A detailed statistical analysis suggested Weibull distribution functions provide the best fit. For the plain specimens the Weibull ' $\beta$ ' exponent was unity suggesting an exponential decay in failure rate.

Tables 4 and 5 also contain measurements made of pore size and pore distance from the specimen outer surface. The pore area was calculated by constructing an elliptical shape around the pore with the major and minor axes matching the extremities of the pore. The areas, therefore, may overestimate pore size but do not take into consideration pore dimensions outside the plane of fracture. It might be anticipated that larger pores and short distance should be associated with shorter fatigue lives. An examination of the two tables demonstrates that reality may not be so straightforward. The histograms in figures 12 and 13 summarise measured areas and pore depths for all the $\mathrm{R}=0$ strain control tests at $650^{\circ} \mathrm{C}$ highlighted in figure 8 .

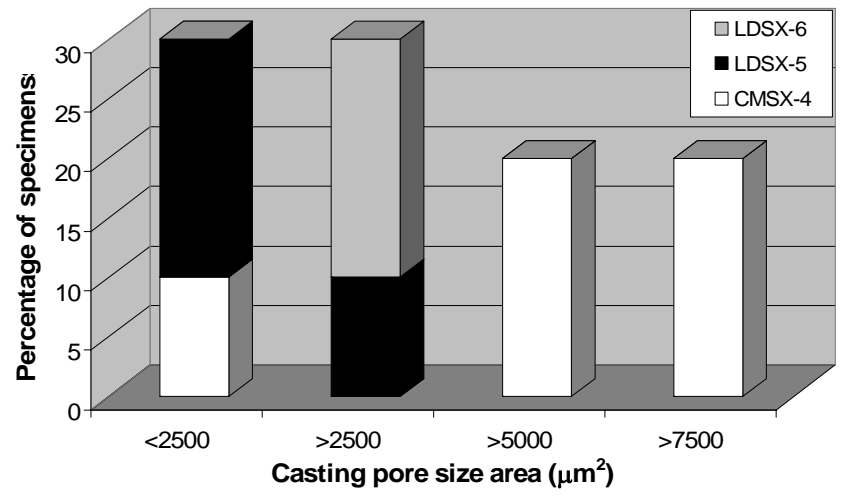

Figure 12. Critical casting pore area values

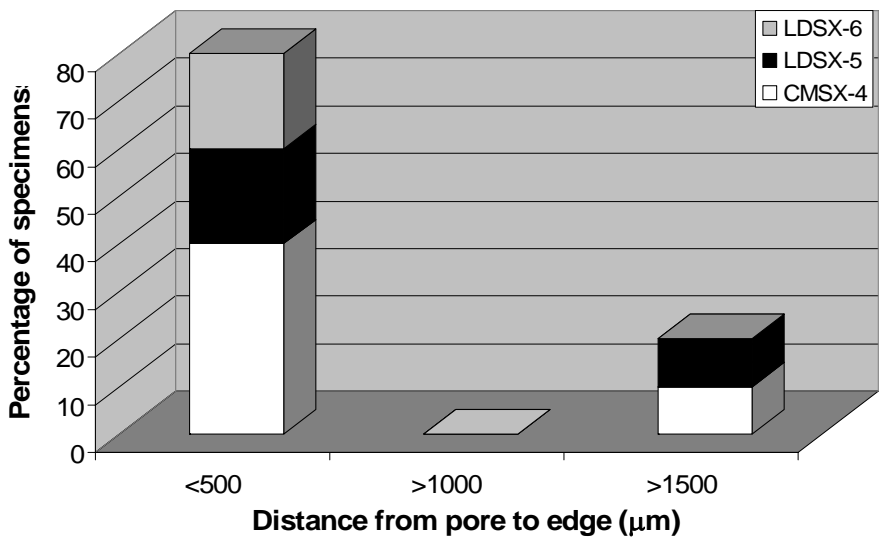

Figure 13. Critical casting pore ligament distance values

\section{Discussion}

\section{$\underline{\text { Life Prediction }}$}

An objective of the work was to explore the effectiveness of strain approaches in the prediction of notch fatigue response. These methods included the Manson-Coffin [3] relationship and the Walker strain [4] equation with the form

$$
\Delta \varepsilon_{\text {walker }}=\frac{\sigma_{\max }}{E}\left(\frac{\Delta \varepsilon_{\text {actual }} E}{\sigma_{\max }}\right)^{\mathrm{m}}
$$

With $\sigma_{\max }$ the maximum cyclic stress at the notch or plain specimen, $\mathrm{E}$ the modulus and $\Delta \varepsilon_{\text {actual }}$ the strain range experienced. The correlating parameter, $\mathrm{m}$, is obtained by curve fitting plain specimen data at different $\mathrm{R}=\left(\frac{\text { min strain or stress }}{\text { max strain or stress }}\right)$ values.

The Walker relationship has the advantage of being able to correlate different $\mathrm{R}$ values. Figure 14 illustrates the Walker predictions of CMSX4 notch data at $650^{\circ} \mathrm{C}\left(\mathrm{K}_{\mathrm{t}}=2.3\right)$ and $800^{\circ} \mathrm{C}$ $\left(\mathrm{K}_{\mathrm{t}}=2.38\right)$ based on the strain control results in Figure 8 and the cyclic stress-strain curves in Figure 6 and 7.

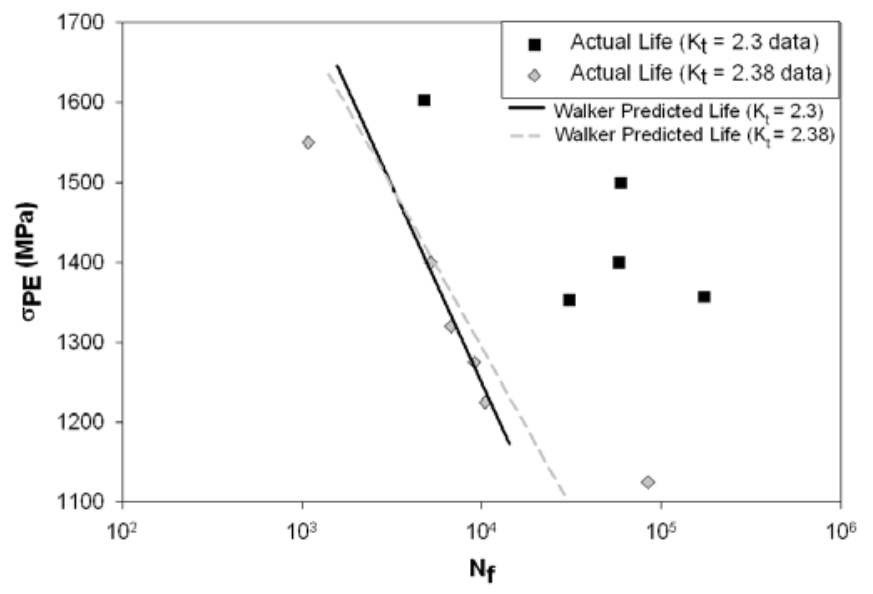

Figure 14. Walker strain predictions of CMSX4 notch lives at $650^{\circ} \mathrm{C}$ and $800^{\circ} \mathrm{C}$

While the predictions at $800^{\circ} \mathrm{C}$ are generally acceptable, at $650^{\circ} \mathrm{C}$ they consistently underestimate measured lives. This discrepancy is attributed to stress conditions associated with the pores. At $800^{\circ} \mathrm{C}$, the alloys cyclically soften. This must be due to enhanced dislocation mobility and plastic deformation (figure 7). It is speculated that as a consequence there will be a significant redistribution of stress thereby diminishing the stress concentration caused by pores. This appears the case in Figure 15 which illustrates plain data at $800^{\circ} \mathrm{C}$ and summarises initiation sites. Clearly the pores do not degrade the fatigue response with respect to the surface. They, therefore, appear to provide a 'free' surface for crack initiation without imposing a significantly higher stress locally. 


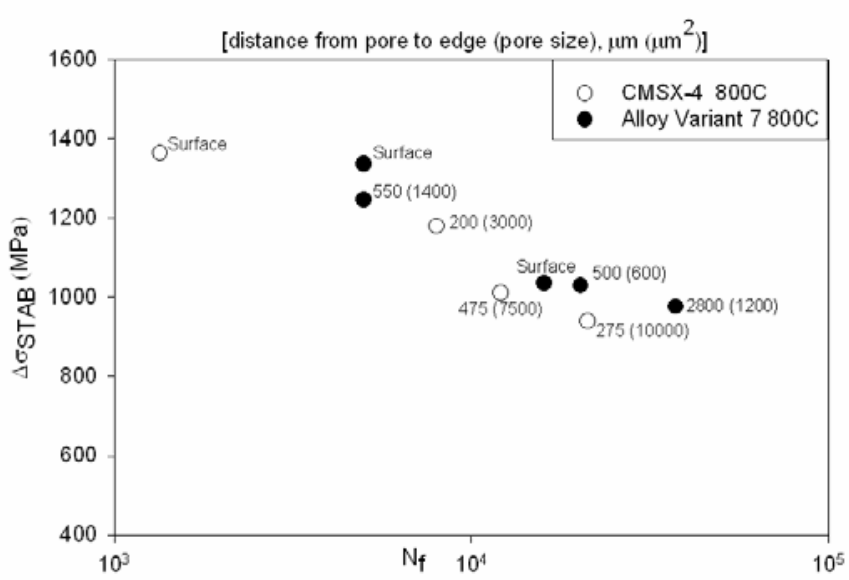

Figure 15. Comparison of surface and subsurface initiation sites in CMSX4 and alloy variants at $800^{\circ} \mathrm{C}$

In contrast, at $650^{\circ} \mathrm{C}$ the strain control data cyclically hardens. The mechanical response, therefore, become more elastic so that any discontinuity in the microstructure acts as a stress raiser. A separate finite element analysis suggests that pores can impose a stress concentration factor $\geq 2$ at the pore surface. The under prediction of the notch behaviour through application of the Walker expression is a consequence. The Walker exponent is derived from plain specimen data. Plain specimens have a bigger stressed volume than the notches and hence a greater likelihood of a larger defect. It is, therefore, not surprising that the predicted lives fall short of the measured notch behaviour.

\section{Correlating Pore Impact}

It was shown in Tables 4 and 5 that the dependence of fatigue performance on pore size and position is not necessarily straightforward. However, intuitively, fatigue lives should decrease as pore size increases but increase as pore distance (or ligament) from the surface increases. On this basis, the fatigue lives for the repeat plain and notched specimens were expressed in terms of the ratio (ligament/pore area). Thus as the ratio increases the fatigue lives should also increase. The outcome is illustrated in figure 16 for plain specimens and in figure 17 for the notched specimens. The increasing trend is evident. Furthermore correlation coefficients in excess of 0.9 emphasise the strength of the correlation.

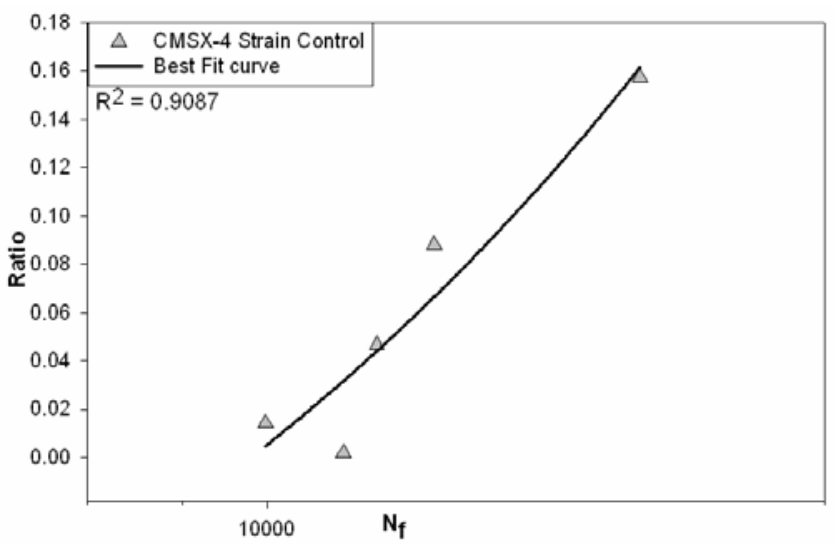

Figure 16. Ligament / Pore Area Ratio versus life for CMSX-4 plain specimens

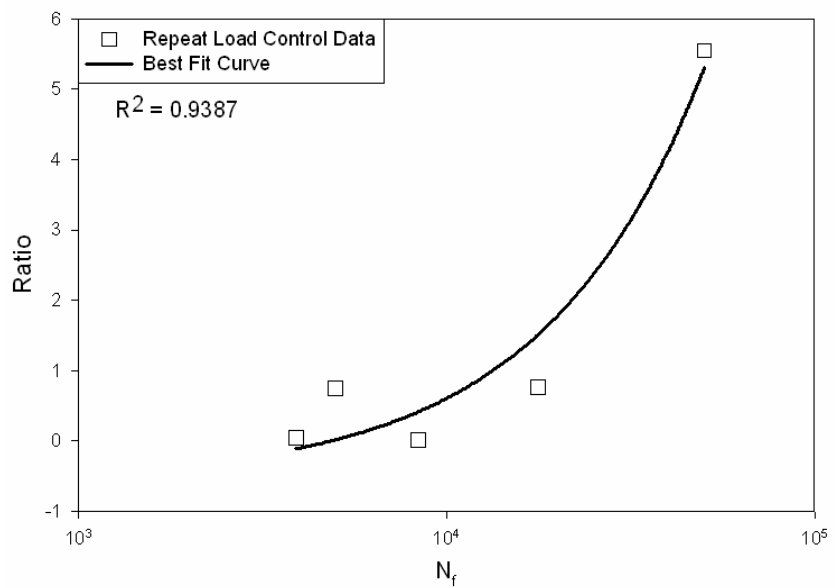

Figure 17. Ligament / Pore Area Ratio versus life for CMSX-4 $\mathrm{K}_{t}$ $=3.6$ notched specimens

\section{Damage Tolerance}

In general, defect situations are generally assessed by the application of fracture mechanics through equations of the form

$$
\frac{\mathrm{da}}{\mathrm{dN}}=\mathrm{C} \Delta \mathrm{K}^{\mathrm{m}}
$$

With $\mathrm{da} / \mathrm{dN}$ the rate of crack propagation, $\mathrm{C}$ and $\mathrm{m}$ constants and $\Delta \mathrm{K}$ the stress intensity factors [5]. Through integration of this equation, knowledge of $\mathrm{m}$ and $\mathrm{c}$ from laboratory experiments and an expression for $\Delta \mathrm{K}$, the residual lives of specimens and components can be calculated through the following equation.

$$
\Delta \mathrm{N}=\frac{1}{\mathrm{C} \Delta \sigma^{\mathrm{m}} \mathrm{Y}^{\mathrm{m}}}\left\{\frac{\mathrm{a}_{1}^{(1-\mathrm{m} / 2)}-\mathrm{a}_{0}{ }^{(1-\mathrm{m} / 2)}}{(1-\mathrm{m} / 2)}\right\}
$$

with $\mathrm{Y}$ the geometry term in an expression for the stress intensity factor of the form $\Delta K=Y \Delta \sigma \sqrt{\mathrm{a}}$

Brandt [6] has derived a stress intensity expression that is appropriate for the current situation:

$$
\Delta \mathrm{K}=(0.78+0.0395 \mathrm{D} / \mathrm{L}) \Delta \sigma \sqrt{\mathrm{D}}
$$

which highlights a dependence on ligament distance, L, and pore size, D. For convenience, in the present analysis it was assumed that the initial and growing crack shape was circular with the radius $\mathrm{a}=\mathrm{D} / 2=\sqrt{\text { poresize } / \pi}$. On this basis, the geometry term has the form

$$
\mathrm{Y}=\sqrt{2}\{0.78+0.0790 \mathrm{a} / \mathrm{L}\}
$$

Since both a and L are changing as the crack grows, the propagation life is calculated incrementally. For each increment the conditions are assumed to be constant. Clearly, a smaller increment size will give a more accurate calculation. On this basis the crack size, $\mathrm{a}_{1}$, at the end of an increment of crack growth, $\Delta \mathrm{N}$, is given by: 


$$
\mathrm{a}_{1}=\left[\Delta \mathrm{NC} \Delta \sigma^{\mathrm{m}} \mathrm{Y}^{\mathrm{m}}(1-\mathrm{m} / 2)+\mathrm{a}_{0}{ }^{(1-\mathrm{m} / 2)}\right]^{1 / \mathrm{m}-2}
$$

with $\mathrm{a}_{0}$ the crack size at the start of incremental growth. By summing all the increments, the total crack propagation life can be calculated.

Using this expression and measured crack growth rates at $650^{\circ} \mathrm{C}$ on CMSX4 corner crack specimens, shown in figure 18 , the correlation recorded in table VI was obtained.

Table VI. Calculated crack propagation lives in CMSX 4 at $650^{\circ} \mathrm{C}$

\begin{tabular}{|c|c|c|c|c|c|}
\hline $\begin{array}{c}\text { Pore } \\
\text { Area } \\
\left(\mu \mathrm{m}^{2}\right)\end{array}$ & $\begin{array}{c}\text { Ligament } \\
\text { Distance } \\
(\mu \mathrm{m})\end{array}$ & $\mathrm{m}$ & $\mathrm{c}$ & $\begin{array}{c}\text { Calculated } \\
\mathrm{N}_{\mathrm{f}}\end{array}$ & $\begin{array}{c}\text { Measured } \\
\mathrm{N}_{\mathrm{f}}\end{array}$ \\
\hline 19905 & 1750 & 2.68 & $5.1 \mathrm{E}-11$ & 16063 & 12311 \\
\hline 19905 & 1750 & 2.19 & $4.1 \mathrm{E}-10$ & 4330 & 12311 \\
\hline
\end{tabular}

Table VI contains two sets of $\mathrm{m}$ and $\mathrm{C}$ values. This reflects previously reported work [7] that the rate of propagation is influenced by the direction in which the crack is growing on the (001) plane. Clearly cracks growing form a buried flow will be influenced by this apparent anisotropy which in turn will impact on the measured lives. The calculated lives span the measured values perhaps reflecting the anisotropic influence. Thus the analysis is a promising but preliminary evaluation. A more detailed assessment will follow in future publications.

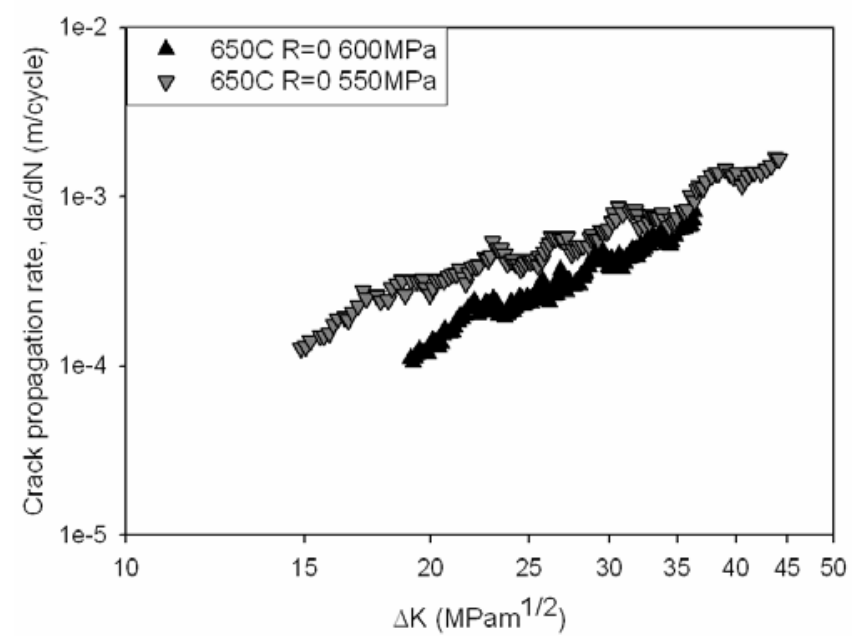

Figure 18. Crack Propagation rates for $\mathrm{CMSX} 4$ at $650^{\circ} \mathrm{C}$

\section{Conclusions}

The paper explores the strain control fatigue behaviour of CMSX4 and several alloy single crystal variants. It clearly demonstrates differences in the cyclic fatigue response at $650^{\circ} \mathrm{C}$ and $800^{\circ} \mathrm{C}$ which is related to increased dislocation mobility at $800^{\circ} \mathrm{C}$. The different response impacts on the role that casting pores play in the initiation of fatigue cracks. This is illustrated through application of the Walker strain relationship which is effective at $800^{\circ} \mathrm{C}$ but under predicts notch lives at $650^{\circ} \mathrm{C}$ possibly because of 'weak' link concepts associated with volume differences. Two approaches to life predictions of the pores are discussed. One relates fatigue lives to the ratio ligament distance to pore area. The second demonstrates the effectiveness of fracture mechanics and the application of crack growth data in calculating residual propagation lives.

\section{Acknowledgements}

The authors gratefully acknowledge the support and assistance given by Rolls-Royce plc in this work and for the DARP funding from the EPSRC.

\section{References}

1. P.J. Hurley, M.T. Whittaker, S.J. Williams and W.J. Evans, "Prediction of fatigue initiation lives in notched Ti 6246 specimens," International Journal of Fatigue, 30(2008), 623-634.

2. W.J. Evans, J.P. Jones and S.J. Williams, "The interaction between fatigue, creep and environmental damage in Ti6246 and Udimet 720Li", International Journal of Fatigue”, 27(2005), 1473-1484.

3. S.S. Manson, "Fatigue: a complex subject - some simple approximations," Exp. Mech,, 5(1965), 193-226.

4. K. Walker, "Effects of environment and complex load history on fatigue life," ASTM STP 462(1970) 1-14.

5. P.C. Paris and F. Erdogan, "A critical analysis of crackpropagation laws", Journal of Basic Engineering, 85, (1963), 528-534.

6. D.E. Brandt, "The development of a turbine wheel design criterion based on fracture mechanics," Journal of Engineering for Power, Trans. ASME, 93(1971), 411.

7. M.R. Joyce, X Wu, P.A.S. Reed, "The effect of environment and orientation on fatigue crack growth behaviour of CMSX4 nickel base single crystal at $650^{\circ} \mathrm{C}$,", Materials Letters, 58(2003), 99-103. 